\title{
A Case of Individualized Information Monitoring and Customizing System for a News Group
}

\author{
Guoping Xia', Jiangang Shen ${ }^{2}$, and Feng $\mathrm{Lu}^{3}$ \\ 1,2 School of Economics \& Management, BeiHang University, \\ Beijing 100083, China, 1 gxia@buaa.edu.cn, 2 shenjg@buaa.edu.cn \\ 3 Dazhong News Group, Jinan, ShanDong Province, China, \\ lufeng@mail.dzdaily.com.cn
}

\begin{abstract}
Information content service industry is expanding rapidly in China nowadays. The paper describes the monitoring and customizing of information content and designs one of them. The paper investigates the characters, the functions and the performances of the system. Specially, the paper compares the monitoring and customizing system with searching engine in different aspects. The system applied successfully in Dazhong News Group, which is one of the largest news groups in China and publishes eight kinds of newspapers and two periodicals at present. So the applications of the system are illustrated briefly. Finally, the paper introduces the multimedia calling center of DaZong News Group and Information Platform, which is one of the largest information service platforms in China.
\end{abstract}

\section{Introduction}

Information monitoring and customizing technology is a service which continuously obtains and analyzes the information change of monitoring target within the pre-set range in certain periods. In fact, the traditional press cutting service is a kind of information monitoring service which provides enterprises with information of industry and rivals, although it is much slower than information monitoring and customizing system.

Generally, information monitoring and customizing system monitors public media, including newspaper, radio, TV, publications, research report, websites of government department, enterprise recruiting advertisement, industry supervising organization and rivals, and so on. According to different intentions, information monitoring can be classified into personal interests (stars, work environment, etc.)

Please use the following format when citing this chapter:

Xia, G., Shen, J., Lu, F., 2006, in International Federation for Information

Processing, Volume 205, Rescarch and Practical Issucs of Enterprise Information Systems, eds.

Tjoa, A.M., Xu, L., Chaudhry, S., (Boston:Springer), pp.591-595. 
monitoring, government policy consensus monitoring, enterprise competition environment monitoring, etc. At present, the most common use is enterprise competition environment monitoring, which in detail includes rivals/partners/ supervisors monitoring, industry/policy environment monitoring, market/business environment monitoring, trademark monitoring, technology trends monitoring, consuming environment monitoring, etc. The paper describes a monitoring and customizing system of information content and implements it in a news group in China.

\section{Main Functions of the System}

It is an information content service system based on Internet with functions of real time information collection, self-definition topic classification, personalized distribution and knowledge management. By using new technologies in both Chinese and English information processing, it continuously traces thousands of websites of media, enterprise and business in tens of countries and districts, automatically filters information content, eliminates useless pages, precisely obtains target information, and matches them with user's requirement to guarantee users to get the information needed in time. At present, the amount of new information collected and monitored each day is about 30,000 pieces.

\subsection{Information monitoring service}

The service includes news monitoring, web pages monitoring and web station scan monitoring, etc. The frequency could be from several times a day to non-stop, according to users' requirement. With enough bandwidth, monitoring cycle could be less than 3 minutes.

\subsection{Information customizing management}

User customization is a personalized service interfaces, including:

- Topic object dictionary of complete self-definition

The dictionary supports the mixed coding of Chinese and English, and the topic word supports kinds of combinations of 'and, or, not', like 'A+B-C'.

- Management of topic customization

Users can set monitoring target themselves, and add, delete and modify the settings. They can also set hundreds of targets easily through 'quick customization'.

- Scanning of websites in English, simplified and traditionalized Chinese

- Customization of scanning scope

Users can change monitoring scope by key words. And they can also adjust monitoring scope by categories.

- Intelligent filter of websites

- Automatic adjust of website scanning order

- Automatic expansion of scanning scope 


\subsection{Monitoring result management}

- Create reports of canning results automatically

This way, users can not only read, repeat use, download and save those results, but also do secondary search and develop through them.

- Edit news-re-editing monitoring results.

- Label and sort news according to importance

- Eliminate repetition automatically

- Analyze statistics of monitoring results

- "Push" information automatically

\section{Comparison of the System vs. Search Engine}

The system makes users describe their information demands in natural-like languages, so it will send the matched information to users regularly.

The differences between search engine and information monitoring and customizing system can be seen from Table 1 .

Table 1. Comparison of information monitoring and customizing system vs. search engine

\begin{tabular}{|c|c|c|}
\hline & Search Engine & $\begin{array}{l}\text { Information monitoring and } \\
\text { customizing system }\end{array}$ \\
\hline Using motivation & Query old information & Tracing the latest information \\
\hline Obtaining method & Users look for information & $\begin{array}{l}\text { Search and analyze information } \\
\text { and "push" the results to users. }\end{array}$ \\
\hline $\begin{array}{l}\text { Information } \\
\text { timeliness }\end{array}$ & $\begin{array}{l}\text { Days or weeks to get the } \\
\text { information into database. }\end{array}$ & $\begin{array}{l}\text { Obtain, process and inform the } \\
\text { latest information in real time. }\end{array}$ \\
\hline Information scope & $\begin{array}{l}\text { The latest information only } \\
\text { inside the website. }\end{array}$ & $\begin{array}{l}\text { The latest information in all } \\
\text { dynamic websites, covering } \\
\text { thousands of medias and channels }\end{array}$ \\
\hline Convenience & Users search again and again. & $\begin{array}{l}\text { The system informs automatically } \\
\text { according to users' demand. }\end{array}$ \\
\hline $\begin{array}{l}\text { Query target } \\
\text { Information } \\
\text { management }\end{array}$ & $\begin{array}{l}\text { One topic at one time. } \\
\text { Simple display of mass } \\
\text { repeated information. }\end{array}$ & $\begin{array}{l}\text { Traces a lot of topics at one time. } \\
\text { Provide function of personalized } \\
\text { knowledge management. }\end{array}$ \\
\hline Query results & $\begin{array}{l}\text { Ranked by weight, but no } \\
\text { management function. } \\
\text { New/old, read/unread could not } \\
\text { be distinguished. }\end{array}$ & $\begin{array}{l}\text { Provide functions of repetition } \\
\text { auto-elimination, sentence expert, } \\
\text { and personalized knowledge } \\
\text { management. }\end{array}$ \\
\hline $\begin{array}{l}\text { Results } \\
\text { management }\end{array}$ & $\begin{array}{l}\text { Lost the process and results } \\
\text { after query finished. }\end{array}$ & $\begin{array}{l}\text { Save information, create reports } \\
\text { and monitoring knowledge base. }\end{array}$ \\
\hline
\end{tabular}




\section{Main performance parameters of the system}

- News websites coverage

At present, it covers 25 countries (districts), including English, simplified and traditionalized Chinese, more than 5,000 Chinese news channels and 4,000 English channels.

- The amount of news monitored everyday

There are more than 35,000 pieces of news monitored everyday, about $53 \mathrm{MB}$ news data.

- News monitoring cycle

The cycle time is less than 5 minutes, which depends on net bandwidth and server hardware. A PC server of single CPU can finish a monitoring cycle in about 600 seconds with enough bandwidth.

- Customized topic matching time

It is about $6 \mu$ s (microsecond, based on Intel Celeron 400) for each user.

- Number of customized topic matched

Customized topic of each user can be the logic combination of any topics, which could be several, tens of, even hundreds of, according to requirement.

\section{System application analysis}

The system includes five kinds of monitoring services:

- News customizing service for news enterprises and individual customers.

- Business and policy information customizing service for enterprises

- Industry and field information customizing service for governments

- Academic customizing service for research and education institutes

- Personalized and special topic information service for individuals.

\section{Integrated information platform}

Dazhong News Group built the information platform, which is one of the biggest multi-media IP calling center in eastern China. It broke through the single plane media mode of news group, founded a solid information service platform composed of one platform (a media platform), two bases (multi-media information database and profession information database), three channels (network, short messages and calling center), and greatly improved integration service level and economic benefit.

Based on IP media calling center and short message center, it integrates services like information query, customer requisition, transaction acceptance and solution, logistics and distribution, intelligent office, value-added business and electronic commerce. In order to dig customers' potentiality, guarantee customer loyalty and increase media competition ability, it provides several kinds of interview and 
feedback methods, such as telephone, fax, Internet, E-mail, etc.; offers enterprises with information service which is "one-stop", personalized, friendly and intelligent.

On the basis of the platform, several new businesses were exploited:

- News clue collecting

- Member club

- Consultation

- Investigation

- Complain

- Electronic yellow page

- Medical treatment website

- Tickets Service

- Electronic shopping

Dazhong information center in China was built in June, 2004, when it is time for college entrance exam. The consulting meeting of college entrance exam co-hosted by Dazhong information center and Qilu Evening Newspaper, integrated kinds of media channels such as newspaper media, Internet, calling center, short message center, etc, centralized the recruit specialists of each college, and built a direct communication bridge between recruit specialists and the students as well as their parents. During the meeting, the consulting calls amount reached more than 5,600 each minute, and the short messages more than 6,000. As a result, the society showed a very good feedback of the meeting.

\section{References}

1. S. He, Supply Chain Management For Information Service, Journal of Information 20(5), 566-571 (2001).

2. T. Jiang, Supply Chain Operation Reference Model, (June 27, 2001) http://www.cio.cn/kejian/jdkc/scm/images/ppt01.files/frame.htm\#slide0003.htm.

3. J. Huang, New Standard Of Multi-Media For News Industries, (October 26, 2002) http://cnewsml.org/resources/kfwong-2002Oct-te.html. 